\title{
Reduced Density of Platelet-Binding Sites for [3H]Paroxetine in Remitted Bulimic Women
}

\author{
Howard Steiger*,, 1,2,3, Jodie Richardson ${ }^{1,2}$, Mimi Israel ${ }^{1,2,3}$, NMK Ng Ying Kin ${ }^{2,3}$, Kenneth Bruce ${ }^{1,2,3}$, \\ Sandra Mansour ${ }^{1,2}$ and Anne Marie Parent ${ }^{1,2}$ \\ 'Eating Disorders Program, Douglas Hospital, Montreal, Quebec, Canada; ${ }^{2}$ Research Center, Douglas Hospital, Montreal, Quebec, Canada; \\ ${ }^{3}$ Psychiatry Department, McGill University, Montreal, Quebec, Canada
}

\begin{abstract}
Findings show brain serotonin (5-hydroxytryptamine (5-HT)) activity to be altered in individuals who have had bulimia nervosa (BN), even after substantial remission of symptoms. Such findings could reflect persistent sequelae due to BN, or a vulnerability 'trait' that exists independently of active eating-disorder manifestations. We compared women with full-blown $\mathrm{BN}$ (BN; $n=22)$, BN in remission (BN-R; $n=I I)$, and no eating or psychiatric disturbances $(n=22)$ on measures of platelet $\left[{ }^{3} H\right]$ paroxetine binding, eating symptoms and psychopathology. The BN-R group showed normal-range scores on eating and psychopathological symptoms, but reductions in density $\left(B_{\max }\right)$ of binding sites for paroxetine similar to those obtained in the actively ill women. Both BN groups had substantially lower $B_{\text {max }}$ than did healthy controls. Our results corroborate other findings indicating recovered BN patients to have anomalous 5-HT functioning. While such effects could represent a lasting 'injury' to the system, reported covariations between personality traits and 5- $\mathrm{HT}$ indices in BN encourage us to favor the argument that some alterations of 5-HT activity (in this case, consistent with reduced transporter activity) represent a 'trait' associated with the risk of developing BN and/or associated psychopathology.

Neuropsychopharmacology (2005) 30, 1028-1032, advance online publication, 9 February 2005; doi: I 0. I 038/sj.npp. I 300693
\end{abstract}

Keywords: bulimia nervosa; serotonin; platelet paroxetine binding; neurobiology; traits

\section{INTRODUCTION}

Active bulimia nervosa (BN) sufferers display altered serotonin (5-hydroxytryptamine (5-HT)) system functioning, as evinced by reduced platelet binding of 5-HT uptake inhibitors (Marazziti et al, 1988; Steiger et al, 2000), reduced central 5-HT transporter availability (Tauscher et al, 2001), blunted neuroendocrine responses to 5-HT precursors and agonists (Levitan et al, 1997; Steiger et al, 2001a,b), and decreased 5-HT metabolites in cerebrospinal fluid (Jimerson et al, 1992). As food restriction is known to alter central 5-HT activity in animals (Huether et al, 1997; Zhou et al, 1996) and in humans (Goodwin et al, 1987), abnormal 5-HT function in BN could, reasonably, be a consequence of disordered eating. In keeping with this conceptualization, two studies report neuroendocrine responses after 5-HT agonists to be normal in fully recovered bulimics (Kaye et al, 1998; Wolfe et al, 2000), as might suggest the resolution of a disturbance seen in the actively bulimic state.

*Correspondence: Dr H Steiger, Eating Disorders Program, Douglas Hospital, 6875 LaSalle Blvd, Verdun, Quebec H4H IR3, Canada, Tel: + | 514 761 6131 ext. 2895, Fax: + I 5 |4 888 4085,

E-mail: stehow@douglas.mcgill.ca

Received 25 October 2004; revised 5 January 2005; accepted 7 January 2005

Online publication: 13 January 2005 at http://www.acnp.org/citations/ NPPO I I 305040382/default.pdf
In contrast, other studies in recovered $\mathrm{BN}$ patients indicate persistent serotonergic abnormalities-and on indices that (arguably) provide a more direct reflection than do endocrine indices of central serotonergic activity: Positron emission tomography reveals abnormally low 5-HT2a receptor activity following one or more years of abstinence from bulimic symptoms in former bulimics (Kaye et al, 2001) and binge-purge anorexics (Bailer et al, 2004). Likewise, recovered bulimics reportedly show ongoing hypersensitivity to effects of acute tryptophan depletion (Smith et al, 1999), and abnormally high cerebrospinal fluid 5-HT metabolites (Kaye et al, 1998). Kaye et al (2001) proposed that such findings could reflect (a) a lasting 'scar' resulting from having had BN, or (b) a pre-existing, 5-HT-mediated vulnerability 'trait'.

The present study further explored 5-HT status in women showing remission from $\mathrm{BN}$, this time using platelet $\left[{ }^{3} \mathrm{H}\right]$ paroxetine binding. Platelet binding of 5-HT reuptake inhibitors is believed to model aspects of central 5-HT transporter (reuptake) function (Lesch et al, 1993). Previous platelet-binding studies in actively bulimic women have used $\left[{ }^{3} \mathrm{H}\right]$ imipramine (Marazziti et al, 1988) or $\left[{ }^{3} \mathrm{H}\right]$ paroxetine (Steiger et al, 2000, 2001a,b) to show markedly reduced density $\left(B_{\max }\right)$ of binding sites - findings that are compatible with documented reduction of central transporter availability in BN (Tauscher et al, 2001). 


\section{METHODS}

\section{Participants}

All participants in this institutional ethics board approved study provided informed consent, and were free of 5-HT active medications for at least 6 weeks. Women with BNspectrum disorders were recruited at a specialized eating disorders (ED) program. Healthy women (with neither ED nor psychiatric manifestations) were recruited through university classes or newspaper advertisements (to approximate the student/non-student ratio among bulimics). Remitted BN patients consisted of 11 women, formerly meeting full DSM-IV (American Psychiatric Association, 1994) criteria for BN. When tested, these women had been abstinent from bingeing and purging from 3 to 60 months $($ mean $=17.09 \pm 17.85)$, and all had normal menstrual function and body mass (body mass index (BMI) of 19 or more). While three of the BN-R cases were abstinent for less than 6 months, visual inspection of the data, and tests for association between duration of abstinence and density of paroxetine-binding sites (see Results, to follow), suggested no obvious effects of shorter 'duration of abstinence' on findings.

From available samples of women with active DSM-IV BN and healthy non-eating disordered women (recruited during the same time frame as were cases in remission), we selected groups of $n=22$ each, taking care to match as closely as possible for age and BMI $\left(\mathrm{kg} / \mathrm{m}^{2}\right)$ two actively bulimic (BN) and two healthy control (HC) individuals to each of our remitted bulimic (BN-R) cases. Mean ages for the $\mathrm{BN}, \mathrm{BN}-\mathrm{R}$, and $\mathrm{HC}$ groups, respectively, were 27.77 $( \pm 3.70), 28.18( \pm 8.45)$, and $25.0( \pm 5.72)$. Mean BMIs, respectively, were $22.58( \pm 2.11), 22.46( \pm 2.55)$, and 21.99 $( \pm 1.48)$. Neither of the preceding values yielded significant group effects, according to ANOVA tests. Over the 3 months prior to testing, the mean monthly binging in the $\mathrm{BN}$ group was $36.71( \pm 30.01)$. Mean monthly episodes of purging, including vomiting, laxative, or diuretic misuse (computed among purgers only) was $45.54( \pm 49.61)$, and mean monthly vomiting (computed among vomiters only) was $51.99( \pm 47.22)$.

\section{Measures}

Well-validated interviews and scales, chosen for psychometric strengths and familiarity, were used to assess eating and generalized symptomatology. Given a bilingual population, French translations of scales were required. Support for the validity of French translations has been provided elsewhere (Steiger et al, 2000, 2001a, b).

We assessed ED symptoms using the Eating Disorders Examination (EDE: Fairburn and Cooper 1993), a structured interview evaluating criterion ED symptoms (eg, frequency of binge/purge behaviors, weight preoccupation), the Eating Disorders Inventory-2 (EDI-2: Garner, 1991), and the Eating Attitudes Test (EAT-26; Garner et al, 1982). To reflect nutritional status, we computed the BMI. Psychopathological characteristics were assessed using: the Barrat Impulsivity Scale (BIS, version 11: Patton et al, 1995), selected subscales from the Dimensional Assessment of Personality Pathology-Basic Questionnaire (DAPP-BQ;
Livesley et al, 1992) tapping such traits as Compulsivity, Sensation Seeking, and Affective Instability, and the Centre for Epidemiological Studies Depression (CES-D) scale (Weissman et al, 1977). To screen for psychiatric comorbidity, we used a computerized version of the Diagnostic Interview Schedule, Version IV (DIS4: Bucholz et al, 1991; Robins et al, 1981) to guide face-to-face interviews.

\section{Serotonin Measures}

Participants were asked to refrain from coffee, cigarettes, exercise, alcohol, or other drugs on the day of testing. Detailed procedures for blood draws, processing, and $\left[{ }^{3} \mathrm{H}\right]$ paroxetine-binding assays are described elsewhere (Steiger et al, 2000, 2001a, b).

\section{RESULTS}

Table 1 shows the mean $( \pm S D)$ scores for $B N, B N-R$, and HC groups on indices of eating and psychopathological symptoms, and paroxetine-binding density $\left(B_{\max }\right)$ and affinity $\left(K_{\mathrm{d}}\right)$. Isolated missing values appear as variations in NS and df's in the tables. Results of one-way ANOVAs and of Newman-Keuls comparisons among groups are also shown. Group effects on EAT-26, Drive for Thinness, and Interoceptive Awareness scores indicate a progressive reduction, in a statistical sense, in these symptoms across $\mathrm{BN}, \mathrm{BN}-\mathrm{R}$, and then HC groups. The means indicate fullblown eating symptoms in BN cases, and nonclinical-range scores in the BN-R and HC groups (Garner et al, 1982; Garner, 1991). On Bulimia, Interoceptive Awareness, and Body Dissatisfaction, means of BN-R and HC groups did not differ, but were both significantly lower than those in the active BN group. Significant effects obtained on the various psychopathological indices (ie, CES-D, Identity Problems, Affective Instability, Compulsivity, Restricted Expression, and Anxiousness) always showed heightened psychopathology in the BN group, relative to that in either BN-R or HC groups. The latter two groups never differed. A significant group effect on $B_{\max }$ for paroxetine binding differentiated lower density of binding sites in BN and BN-R groups from higher values obtained in HC participants, but not BN and BN-R groups. A plot of results (see Figure 1) shows the scatter of $B_{\max }$ values in BN-R participants to be much like that obtained in active BN cases, and to overlap minimally with scores in HC cases. To verify the extent to which variations in duration of abstinence from bingeing and purging might have influenced $B_{\max }$, we computed the simple correlation between 'duration of abstinence' and $B_{\max }$ values for this group. A nonsignificant correlation was obtained $(r=0.15, p>0.50)$. In addition, visual inspection of scores showed no evidence of systematically lower $B_{\max }$ in the most recently remitted cases. In a related vein, bivariate correlations between Age and BMI, on the one hand, and $B_{\max }$, on the other, were negligible (and nonsignificant) in our $\mathrm{BN}(r=-0.11$ and 0.07 , respectively), BN-R ( $r=0.13$ and -0.13 , respectively) or HC $(r=-0.11$ and 0.14, respectively) samples. Possible effects attributable to Age or BMI variations are, therefore, not indicated.

Data on lifetime history of selected Axis-I syndromes are shown in Table 2. Where empty cells exist, results are not 
Table I Mean (+SD) Scores on Symptom Measures in BN, BN-R and HC Groups

\begin{tabular}{|c|c|c|c|c|c|c|c|}
\hline & Active bulimic (BN) & $\mathbf{N}$ & Remitted bulimic (BN-R) & $\mathbf{N}$ & Healthy control (HC) & $\mathbf{N}$ & $F(d f, D F)$ \\
\hline EAT-26 & $36.43(11.88)^{\mathrm{a}}$ & 22 & $12.03(11.42)^{b}$ & 11 & $3.69(3.47)^{c}$ & 22 & $71.54(2,51)^{* * * * *}$ \\
\hline Drive for thinness & $|4.9|(5.45)^{\mathrm{a}}$ & 22 & $7.25(6.73)^{b}$ & 8 & $1.37(3.25)^{c}$ & 19 & $38.25(2,46)$ **** \\
\hline Bulimia & $10.68(5.34)^{\mathrm{a}}$ & 22 & $3.25(3.11)^{b}$ & 8 & $0.05(0.23)^{c}$ & 19 & $41.16(2,46)^{* * * * *}$ \\
\hline Interoceptive awareness & $12.32(7.94)^{\mathrm{a}}$ & 22 & $5.00(7.35)^{b}$ & 8 & $0.42(0.84)^{b}$ & 19 & $19.64(2,46)$ ***** \\
\hline Body dissatisfaction & $19.0 \mid(6.57)^{\mathrm{a}}$ & 22 & $10.88(7.26)^{b}$ & 8 & $6.26(7.08)^{b}$ & 19 & $17.84(2,46)^{* * * * *}$ \\
\hline Identity problems & $3.36(0.93)^{\mathrm{a}}$ & 22 & $2.16(0.81)^{b}$ & 10 & $1.77(0.73)^{b}$ & 22 & $21.21(2,51)^{* * * *}$ \\
\hline Affective instability & $3.69(0.78)^{\mathrm{a}}$ & 22 & $2.78(0.82)^{b}$ & 10 & $2.43(0.82)^{b}$ & 22 & $\mid 3.90(2,5 \mid)^{* * * * *}$ \\
\hline Stimulus seeking & $2.82(0.97)$ & 22 & $2.32(0.62)$ & 10 & $2.54(0.5 \mathrm{I})$ & 22 & I.72 (2,5I) NS \\
\hline Compulsivity & $3.86(0.92)^{\mathrm{a}}$ & 22 & $3.15(0.42)^{b}$ & 10 & $3.15(0.78)^{b}$ & 22 & $5.29(2,5 \mathrm{I})$ *** \\
\hline
\end{tabular}

Means with different letters in their superscripts differ on Newman-Keuls tests at the 0.05 level or better.

$* 0 \leqslant 0.05$.

*** $p \leqslant 0.01$.

***** $p \leqslant 0.001$.

$\mathrm{NS}=$ nonsignificant.

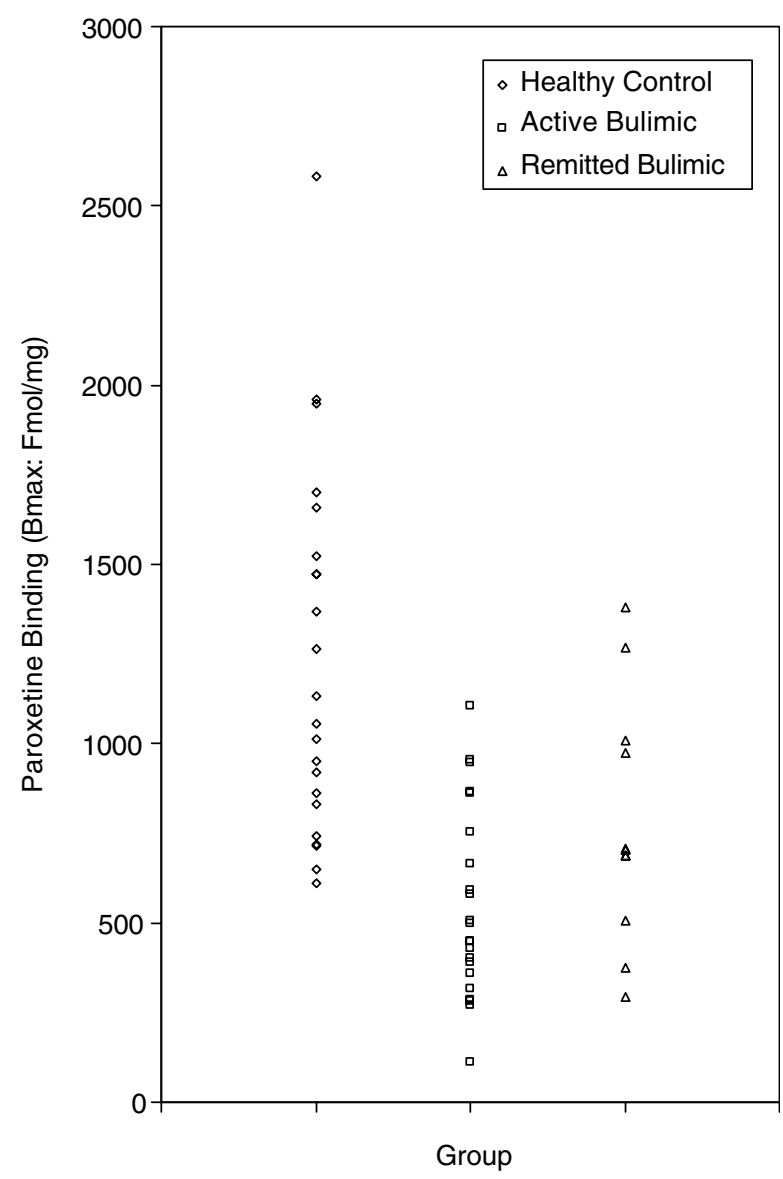

Figure I Scatter of values for density $\left(B_{\max }\right)$ of platelet $\left[{ }^{3} \mathrm{H}\right]$ paroxetinebinding sites (fmol/mg) in $\mathrm{BN}, \mathrm{BN}-\mathrm{R}$, and $\mathrm{HC}$ groups. compared statistically. Meaningful $\chi^{2}$ values could be computed for Major Depression and Post-Traumatic Stress Disorder. That for Major Depression was significant $\left(\chi_{(2)}^{2}=29.99, p<0.001\right)$, with values indicating elevated disorder frequencies in both bulimic groups. That for Post-Traumatic Stress Disorder was also significant $\left(\chi_{(2)}^{2}=7.61, p<0.05\right)$, results more ambiguously implying elevated symptomatology in both bulimic groups.

\section{DISCUSSION}

We find former DSM-IV bulimics 'in remission' to display markedly reduced density of platelet paroxetine-binding sites, comparable to that observed in fully active bulimics, and significantly lower than that obtained in normal eaters. This finding joins an accumulating set of results - generated using cerebrospinal fluid indices of 5-HT metabolism (Kaye et al, 1998), positron emission tomography of 5HT2a receptor binding (Kaye et al, 2001; Bailer et al, 2004), and behavioral measures after tryptophan depletion (Smith et al, 1999) - indicating abnormal 5-HT function in recovered bulimics. To these, our findings contribute evidence to suggest that a stable characteristic of individuals who have had BN (or who are BN-prone), even after substantial remission of symptoms, is low 5-HT reuptake.

Several uncertainties surround the attempt to draw causal inferences from these findings: A first ambiguity concerns the question of how fully 'recovered' were our abstinent patients. While caloric deprivation is known to affect central 5-HT function in animals (Huether et al, 1997; Zhou et al, 1996) and in humans (Goodwin et al, 1987), we are aware of no findings in either the animal or human 
Table 2 Count (Percent) of Cases in BN, BN-R and HC Groups Meeting Criteria for Lifetime Major Psychiatric (Axis I) Disorders

\begin{tabular}{|c|c|c|c|c|c|c|}
\hline & \multicolumn{2}{|c|}{ Active Bulimic (BN) } & \multicolumn{2}{|c|}{ Remitted Bulimic (BN-R) } & \multicolumn{2}{|c|}{ Healthy Control (HC) } \\
\hline & $n(\%)$ & $\mathbf{N}$ & $n(\%)$ & $\mathbf{N}$ & $n(\%)$ & $\mathbf{N}$ \\
\hline Obsessive-compulsive disorder & $5(22.7 \%)$ & 22 & $0(0 \%)$ & 10 & $0(0 \%)$ & 22 \\
\hline Simple phobia & $3(13.6 \%)$ & 22 & $0(0 \%)$ & 10 & $0(0 \%)$ & 22 \\
\hline Panic disorder & $7(31.8 \%)$ & 22 & $2(20.0 \%)$ & 10 & $0(0 \%)$ & 22 \\
\hline Generalized anxiety disorder & $5(22.7 \%)$ & 22 & $0(0 \%)$ & 10 & $0(0 \%)$ & 22 \\
\hline Post-traumatic stress disorder & $8(36.4 \%)$ & 22 & $2(20.0 \%)$ & 10 & | (4.5\%) & 22 \\
\hline
\end{tabular}

literature that would guide assumptions concerning the extent to which such effects may be long-lasting. Similarly, there is little guidance for decisions concerning when to consider an abstinent bulimic 'recovered', or to assume that nutritional sequelae will no longer be influencing a formerly bulimic individual's neurobiological activity. Serotonergic anomalies seen in our remitted bulimic group might, in other words, represent lasting 'injuries' or 'scars', associated with a previous period of nutritional distress.

While the preceding remains a concern, our remitted cases showed substantial freedom from eating and psychopathological symptoms, and a negligible correlation between the duration of abstinence and density of paroxetinebinding sites. At the least, this suggests that strikingly reduced paroxetine-binding density observed in our abstinent patients is unlikely to be attributable solely to residual symptomatology. Furthermore, several forms of evidence would support the concept that persistent 5-HT alterations in former bulimics might actually represent 'trait' variations, rather than eating-disorder sequelae: In various populations, traits such as impulsivity and compulsivity have been linked to altered 5-HT activity (Cloninger et al, 1993; Coccaro et al, 1996). In addition, in bulimic individuals, systematic associations have been reported between traits such as impulsivity or harm avoidance and variations on such indices, such as endocrine responses after a 5-HT agonist (Steiger et al, 2001a), platelet paroxetine binding (Steiger et al, 2001b), 5HT2a receptor activity (Bailer et al, 2004), and even 5-HT transporter gene variations (Steiger et al, 2005). All of the preceding encourage the speculation that an underlying serotonergic anomaly, existing independently of active ED symptoms, might be a risk factor for the development of both $\mathrm{BN}$ and associated trait pathology - and might (in turn) explain characteristic comorbidity patterns that emerge in bulimia sufferers. Speculations concerning an underlying serotonergic 'trait' ultimately require confirmation from longitudinal data reflecting individuals' premorbid status, family studies reflecting 5-HT status in first-degree relatives, and molecular-genetic studies.

Additional concerns surround the interpretation of our data: Foremost of these is that the value of the present findings rests upon the validity of inferences about central 5 -HT functioning drawn from peripheral indices of 5-HT uptake. Platelet measures have obvious limitations in this regard, but there is also support for the belief that such indices provide an approximation to central 5-HT activity: (1) Platelet-binding sites display morphological and kinetic similarities to central 5-HT transporter sites (Lesch et al, 1993). (2) Previous demonstrations of reduced plateletbinding density for selective 5-HT reuptake inhibitors in actively bulimic women (Marazziti et al, 1988; Steiger et al, 2000, 2001b, 2005) are consistent with documented reduction of central transporter availability in BN (Tauscher et al, 2001). (3) Peripheral alterations in binding for selective 5-HT reuptake inhibitors correspond to response of depressive symptoms to pharmacotherapy (Freeman et al, 1993). (4) Paroxetine binding in platelets varies systematically with genotypic variations in the serotonin transporter gene promoter, 5HTTLPR (Steiger et al, 2005).

Compared to actively bulimic women, our abstinent bulimics showed relatively normal scores on various psychopathological indices (see Table 1 and 2). Evidence of normalization of psychopathological characteristics is observed in other studies in recovered bulimic patients (Kaye et al, 1998; Lilenfeld et al, 2000), and is therefore not altogether surprising. Nonetheless, a concern arises around the apparent tendency for findings on Axis-I disorders (see Table 2) to suggest that our remitted bulimics may have actually shown lesser lifetime psychopathology than did our active bulimics. If so, there is the possibility that, in selecting a group of bulimic patients who had achieved remission of $\mathrm{BN}$, we may have been sampling from a fundamentally healthier subgroup. This remains a possibility. However, we note that any such tendencies would actually make our results all-the-more striking with respect to the hypothesis that there should exist ongoing reductions of 5-HT reuptake activity in abstinent patients - as this would imply that even less-disturbed bulimics had (and retained) a fundamental anomaly of the 5-HT system. The latter tendency would further disconnect the serotonergic anomaly in question from the sequelae of severe eatingdisorder symptoms, and point to a possibly stable characteristic of the bulimia-prone individual.

\section{ACKNOWLEDGEMENTS}

This research was supported by a grant from the Canadian Institutes for Health Research (No. MA 15368). Preliminary 
results from this study were presented at the annual meeting of the Eating Disorders Research Society, Amsterdam, the Netherlands, October 9, 2004. We thank Debra Gartenberg, Leechen Faarkas, Heidi Shapiro, Julia Finkelstein, Andrea Byrne, Stephanie Levine-Grant, Melanie Aubut, and Susan Amro for their contributions.

\section{REFERENCES}

American Psychiatric Association (1994). Diagnostic and Statistical Manual of Mental Disorders, 4th edn. American Psychiatric Press: Washington, DC.

Bailer UF, Price JC, Meltzer CC, Mathis CA, Frank GK, Weissfeld L et al (2004). Altered 5-HT (2A) receptor binding after recovery from bulimia type anorexia nervosa: relationships to harm avoidance and drive for thinness. Neuropsychopharmacology 29: $1143-1155$.

Bucholz KK, Robins LN, Shayka JJ, Przybeck TR, Heltzer JE, Goldring E et al (1991). Performance of two forms of a computer psychiatric screening interview: Version 1 of the DISSI. J Psychiatr Res 25: 117-129.

Cloninger CR, Svrakic DM, Przybeck TR (1993). A psychobiological model of temperament and character. Arch Gen Psychiatry 50: $975-990$.

Coccaro E, Kavoussi RJ, Sheline YI, Lish JD, Csernansky JG (1996). Impulsive aggression in personality disorder correlates with tritiated paroxetine binding in the platelet. Arch Gen Psychiatry 53: 531-536.

Fairburn C, Cooper P (1993). The eating disorders examination. In: Fairburn C, Wilson G (eds). Binge Eating: Nature, Assessment and Treatment, 12th edn. Guilford: New York. pp 317-360.

Freeman A, Stankovic S, Bradley R, Zhang G-Z, Libb J, Nemeroff C (1993). Tritiated platelet imipramine binding and treatment response in depressed outpatients. Depression 1: 20-23.

Garner DM (1991). Eating Disorder Inventory-2: Professional Manual. Psychological Assessment Resources: Odessa, FL.

Garner DM, Olmsted M, Bohr Y, Garfinkel P (1982). The eating attitudes test: psychometric features and clinical correlates. Psychol Med 12: 871-878.

Goodwin GM, Fraser S, Stump K, Fairburn CG, Elliot JM, Cowen PJ (1987). Dieting and weight loss in volunteers increases the number of alpha2-adenoreceptors and 5-HT receptors on blood platelets without effect on $\left[{ }^{3} \mathrm{H}\right]$-imipramine binding. J Affect Disord 12: 267-274.

Huether G, Zhou D, Schmidt S, Wiltfang J, Rüther E (1997). Longterm food restriction down regulates the density of serotonin transporters in the rat frontal cortex. Biol Psychiatry 41: $1174-1180$

Jimerson DC, Lesem MD, Kaye WH, Brewerton TD (1992). Low serotonin and dopamine metabolite concentrations in cerebrospinal fluid from bulimic patients with frequent binge episodes. Arch Gen Psychiatry 49: 132-138.

Kaye WH, Frank GK, Meltzer CM, Price JC, McConaha CW, Crossan PJ et al (2001). Altered serotonin 2A receptor activity in women who have recovered from bulimia nervosa. Am J Psychiatry 158: 1152-1155.
Kaye WH, Greeno CG, Moss H, Fernstrom JD, Fernstrom MH, Lilenfeld LR et al (1998). Alterations in serotonin activity and psychiatric symptoms after recovery from bulimia nervosa. Arch Gen Psychiatry 55: 927-935.

Lesch KP, Wolozin BL, Murphy DL, Reiderer P (1993). Primary structure of the human platelet serotonin uptake site: identity with the brain serotonin transporter. $J$ Neurochem 60: 2319-2322.

Levitan RD, Kaplan AS, Joffe RT, Levitt AJ, Brown GM (1997). Hormonal and subjective responses to intravenous metachlorophenylpiperazine in bulimia nervosa. Arch Gen Psychiatry 54: 521-527.

Lilenfeld LR, Stein D, Bulik CM, Strober M, Plotnicov K, Pollice C et al (2000). Personality traits among currently eating disordered, recovered and never ill first-degree female relatives of bulimic and control women. Psychol Med 30: 1399-1410.

Livesley WJ, Jackson DN, Schroeder ML (1992). Factorial structure of traits delineating personality disorders in clinical and general population samples. J Abnormal Psychol 101: 432-440.

Marazziti D, Macchi E, Rotondo A, Placidi GF, Cassano GB (1988). Involvement of the serotonin system in bulimia. Life Sci 43: 2123-2126.

Patton JH, Stanford MS, Barrat ES (1995). Factor structure of the Barrat Impulsiveness Scale. J Clin Psychol 51: 768-774.

Robins LN, Heltzer JE, Croughan J, Ratcliff KS (1981). National institute of mental health diagnostic interview schedule. Arch Gen Psychiatry 38: 381-389.

Smith KA, Fairburn CG, Cowen PJ (1999). Symptomatic relapse in bulimia nervosa following acute tryptophan depletion. Arch Gen Psychiatry 56: 171-176.

Steiger H, Joober $\mathrm{R}$, Israël $\mathrm{M}$, Young $\mathrm{SN}$, Ng Ying Kin NMK, Gauvin L et al (2005). The 5HTTLPR polymorphism, psychopathological symptoms, and platelet $\left[{ }^{3} \mathrm{H}-\right]$ paroxetine binding in bulimic syndromes. Int J Eating Disord 1: 57-60.

Steiger H, Koerner NM, Engleberg M, Israël M, Ng Ying Kin NMK, Young SN (2001a). Self-destructiveness and serotonin function in bulimia nervosa. Psychiatry Res 103: 15-26.

Steiger H, Leonard S, Ng Ying Kin NMK, Ladouceur C, Ramdoyal D, Young SN (2000). Childhood abuse and tritiated paroxetine binding in bulimia nervosa. J Clin Psychiatry 61: 428-435.

Steiger H, Young SN, Ng Ying Kin NMK, Koerner N, Israel M, Lageix $\mathrm{P}$ et al (2001b). Implications of impulsive and affective symptoms for serotonin function in bulimia nervosa. Psychol Med 31: 85-95.

Tauscher J, Pirker W, Willeit M, de Zwaan M, Bailer U, Neumeister A et al (2001). Beta-CIT and single photon emission computer tomography reveal reduced brain serotonin transporter availability in bulimia nervosa. Biol Psychiatry 49: 326-332.

Weissman MM, Sholomskas D, Pottenger M, Prusoff BA, Locke BZ (1977). Assessing depressive symptoms in five psychiatric populations: a validation study. Am J Epidemiol 106: 203-214.

Wolfe BE, Metzger ED, Levine JM, Finkelstein DM, Cooper TB, Jimerson DC (2000). Serotonin function following remission from bulimia nervosa. Neuropsychopharmacology 22: 257-263.

Zhou D, Huether G, Wiltfangt J, Hajak G, Ruther E (1996). Serotonin transporters in the rat frontal cortex: lack of circadian rythmicity but down-regulation by food restriction. J Neurochem 67: 656-661. 